\title{
Patellofemoral Arthroplasty: Current Concepts and Review of the Literature
}

\author{
Gabriele Pisanu ${ }^{1}$ Federica Rosso ${ }^{1}$ Corrado Bertolo ${ }^{1}$ Federico Dettoni ${ }^{1}$ Davide Blonna ${ }^{1}$ \\ Davide Edoardo Bonasia ${ }^{1}$ Roberto Rossi ${ }^{1}$ \\ ${ }^{1}$ Department of Orthopaedics and Traumatology, University of Study \\ of Turin, Ao Mauriziano Umberto I, Turin, Italy \\ Address for correspondence Gabriele Pisanu, MD, Corso Nizza 5, \\ Cuneo 12100, Italy (e-mail: gabriele.pisanu@libero.it).
}

Joints 2017;5:237-245.

\begin{abstract}
Patellofemoral osteoarthritis (PFOA) can be associated with anterior knee pain, stiffness, and functional impairment. Some authors report that PFOA affects approximately $9 \%$ of patients older than 40 years with a greater prevalence in females. Etiology of PFOA is multifactorial and is related to the presence of abnormal stresses at the PF joint due to knee- and patient-related factors. The need for a joint preserving treatment by isolated replacement of the injured compartment of the knee led to the development of PF arthroplasty (PFA). When a correct PF replacement is performed, PFA preserves physiologic tibiofemoral joint, thus allowing patients for a rapid recovery with a high satisfaction. The outcomes for PFA are quite variable with a trend toward good to excellent results, mainly owing to the improvement in surgical techniques, patient selection, and implant design. The development of the second generation of

Keywords

- patellofemoral

- osteoarthritis

- replacement

- arthroplasty

- knee

PFA improved the outcomes, which is attributed to the different trochlear designs. Recently, encouraging results have been provided by the association of PFA and unicompartmental knee arthroplasty (UKA). In many studies, the main cause of PFA failure is progression of tibiofemoral OA. The aim of this brief review of literature is to summarize the clinical features, indications and contraindications, surgical techniques, complications, and outcomes of PFA.
\end{abstract}

\section{Introduction}

Patellofemoral (PF) osteoarthritis (OA) can be associated with anterior knee pain, stiffness, and functional impairment. ${ }^{1}$ Some authors report that approximately $9 \%$ of patients older than 40 years are affected by PFOA. ${ }^{2}$ Other authors have reported an incidence ranging from 2 to $11 \%$ in men and from 8 to $24 \%$ in women older than 55 years. ${ }^{3,4}$ The higher incidence in female patients may be related to a higher incidence of PF malalignment and dysplasia in this population. ${ }^{5}$ Furthermore, Kobayashi et $\mathrm{al}^{6}$ in a recent systematic review, including 32 studies, concluded that the prevalence of PFOA was $25 \%$ in the asymptomatic population (age $>20$ years) and $39 \%$ in the symptomatic population (age $>30$ years).

The development of PFOA is related to the presence of abnormal PF joint stress, which can be due to excessive amount or inadequate dispersion of forces. The cause of these abnormal stresses is multifactorial, including both knee- and patient-related risk factors. ${ }^{7}$

Among the patient-related risk factors, increased body mass index (BMI) surely increased the forces on the PF joint during weight-bearing activities. ${ }^{8,9}$ Some authors outlined female gender and increased age to be possible risk factors for PFOA, as well as activities involving increased load on PF joint (i.e., descending stairs). ${ }^{7}$ Previous trauma to the PF joint (i.e., patellar fracture or dislocation) has also been related to the development of PFOA. ${ }^{10,11}$

Among knee-related risk factors, increased rate of PFOA has been reported in patients who underwent anterior cruciate ligament reconstruction (ACLR), with a median prevalence of up to $50 \%$ at 10 to 15 years after surgery. ${ }^{12}$ Quadriceps and hip abductor weakness has also been related to PFOA, as well as ileotibial band and hamstring contracture. ${ }^{7}$ However, the most important knee-related risk factor is the presence of PF published online October 4, 2017
DOI https://doi.org/ 10.1055/s-0037-1606618. ISSN 2282-4324.
Copyright ( 2017 Georg Thieme Verlag KG Stuttgart · New York

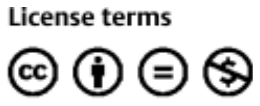


malalignment or trochlear dysplasia, as well as valgus knee alignment and increased femoral anteversion. ${ }^{7,13,14}$

Treatment of PFOA includes nonoperative and surgical options. The nonoperative treatments include exercise, physical therapy, taping, and injections and may result in short-term benefit. ${ }^{14}$ The surgical options range from joint debridement to arthroplasty. However, joint-preserving procedures, including anterior tibial tubercle transfer or cartilage procedures, may lead to insufficient short-term improvement. Total knee arthroplasty (TKA) with patellar replacement is a well-established procedure to treat PFOA, but anterior knee pain may persist in 7 to $19 \%$ of the patients. ${ }^{4,10}$

The need for replacing the PF joint while maintaining a joint kinematic closer to that of the native knee in comparison with TKA led to the development of PF arthroplasty (PFA). ${ }^{4}$ PFA preserves physiologic tibiofemoral joint, thus allowing patients for a rapid recovery with good satisfaction. ${ }^{15}$ Although PFA is considered a valid therapeutic option to treat isolated PFOA, it is indicated in a small and highly selected population.

The first PFA was proposed in 1955 by MacKeever. Despite the initial encouraging results, it was quickly abandoned due to excessive wear in the trochlear groove. ${ }^{16}$ PFA witnessed a rebirth in the 1970s, when the first generation of Richards' prostheses (Smith \& Nephew; Memphis, Tennessee, United States) was introduced and subsequently developed later in the 1990s with the introduction of the second generation of PFA. ${ }^{17,18}$ Although the clinical outcomes after PFA depend primarily on implant design and surgical technique, careful patient selection with very strict inclusion and exclusion criteria is mandatory for long-term survivorship and satisfactory outcomes.

The aim of the this article is to summarize the clinical features, indications and contraindications, surgical techniques, and outcomes of PFA.

\section{Patellofemoral Osteoarthritis}

\section{Patient History and Physical Examination}

Patients with isolated PFOA report an anterior or retropatellar knee pain, usually associated with activities that load the PF joint. ${ }^{4}$ These activities include squatting, ascending or descending stairs, rising from a seated position, or prolonged sitting with flexed knees. ${ }^{4}$ Frequently, some activities, such as full squatting and kneeling, are almost impossible. Pain is less severe when walking on level ground and in standing position with the knee completely extended. ${ }^{11}$ Frequently, patients affected by PFOA experience the worse pain in the early stages of the disease. ${ }^{11}$

During physical examination, it is mandatory to evaluate the entire lower limb, including muscle strength and coronal and PF malalignment (i.e., an increased Q angle). Indeed, the presence of malalignment should be carefully evaluated because in many cases a realignment osteotomy before or in conjunction with PFA may be required. ${ }^{4}$ Crepitus and effusion may be reported, and the patella compression test is often positive in the case of PFOA. The range of motion (ROM) must be investigated, and the examiner should focus on the localization of pain and its correlation to the degree of flexion. Normally, distal lesions (inferior pole) are painful at the first degree of flexion, while proximal lesions are painful at higher flexion. ${ }^{19}$ It is also mandatory to evaluate patella tracking throughout the entire knee ROM to assess maltracking or instability (i.e., the presence of a J sign). ${ }^{20,21}$ Any involvement of the tibiofemoral joint should be ruled out, as well as knee stability, to avoid progressive tibiofemoral OA and/or instability. Furthermore, the neurovascular status, previous scars, and hip and lumbar spine status should be carefully evaluated. ${ }^{4}$

\section{Imaging}

A routine series of conventional X-ray views should be obtained, including standing anteroposterior (AP), flexed weight-bearing posterior-anterior (PA, Rosenberg), lateral, and sunrise (Merchant) views. Both the PF and tibiofemoral joints should be carefully evaluated on these films. Sunrise views at 30 degrees flexion allow for the best assessment, but in some cases, it is useful to take views in various degrees of flexion to better evaluate patellar tilt, subluxation, trochlear dysplasia, or a narrowed joint space. ${ }^{22}$ Lateral view can reveal PF osteophytes, patella height, and joint space narrowing. AP and PA views can reveal a medial or lateral OA. A weightbearing, long-leg view should also be obtained to evaluate lower limb alignment. Some authors suggest additional computed tomography (CT) scan and/or magnetic resonance imaging (MRI) to calculate the tibial tubercle-trochlear grove (TT-TG) distance and evaluate bone stock, rotational malalignment, trochlear dysplasia, and intra-articular structures (articular cartilage, menisci, and ligaments)., 3,21

\section{Patellofemoral Arthroplasty: Indications and Contraindications}

A prerequisite for the success of PFA is a proper patient selection to avoid complications. ${ }^{5,17,23-25}$ The most common indication for PFA is severe primary isolated PFOA that affects daily activities without relief from conservative treatment. PFA is also indicated in patients with posttraumatic PFOA, isolated trochlear dysplasia, patellar subluxation, or failure of previous extensor mechanism unloading procedures, such as Fulkerson or Maquet osteotomy.,11,25-27 Moreover, the ideal patient age ranges from 40 to 60 years. ${ }^{28,29}$

Many contraindications exist to PFA that should always be kept in mind. The presence of tibiofemoral OA is the most common contraindication and the most common cause of PFA failure. ${ }^{5}$ PF malalignment, with an increased $Q$ angle, cannot be corrected by PFA alone; so, it has to be considered as a relative contraindication. On the contrary, mild patellar tilt or subluxation can be corrected at the time of PFA with lateral retinacular release, medialization of the patellar component, or partial facetectomy. ${ }^{4}$ A PFA should preserve normal knee kinematics, joint stability with intact ligaments, and menisci has to be considered as a fundamental prerequisite for PFA. ${ }^{4}$ Furthermore, PFA is contraindicated in the presence of severe uncorrected coronal plane deformity (valgus $>8$ or varus $>5$ degree alignment) or sagittal plane deformity (120 degree flexion with $<10$ degree flexion 
Table 1 Indications and contraindications for PFA

\begin{tabular}{|l|l|}
\hline Indications & Contraindications \\
\hline $\begin{array}{l}\text { Advanced primary } \\
\text { isolated PFOA }\end{array}$ & Absolute contraindications \\
\hline Posttraumatic PFOA & Tibiofemoral OA \\
\hline Trochlear dysplasia & PF malalignment \\
\hline $\begin{array}{l}\text { Patellar subluxation } \\
\text { or mild patellar tilt }\end{array}$ & $\begin{array}{l}\text { Knee instability } \\
\text { (ligaments and/or menisci injuries) }\end{array}$ \\
\hline $\begin{array}{l}\text { Failed extensor } \\
\text { mechanism } \\
\text { unloading } \\
\text { procedures }\end{array}$ & $\begin{array}{l}\text { Limb malalignment } \\
\text { (Valgus deformity }>8 \text { degrees } \\
\text { or varus deformity }>5 \text { degrees) }\end{array}$ \\
\hline Age $>40$ years & Acute infection or CRPS \\
\hline \multirow{5}{*}{} & Relative contraindications \\
\cline { 2 - 3 } & Quadriceps atrophy \\
\cline { 2 - 2 } & Patella baja \\
\cline { 2 - 2 } & BMI $>30$ \\
\hline
\end{tabular}

Abbreviations: BMI, body mass index; CRPS, complex regional pain syndrome; OA, osteoarthritis; PF, patellofemoral; PFA, patellofemoral arthroplasty; PFOA, patellofemoral osteoarthritis.

contracture). ${ }^{4,11,28}$ Active infection and evidence or high suspicion of chronic regional pain syndrome are also contraindications to PFA. ${ }^{11,23}$ Quadriceps atrophy, patellar tendon scarring, patella baja, and excessive BMI (>30) represent relative contraindications to PFA, as have been correlated to poorer outcome. ${ }^{11,23}$ Hence, the ideal candidate for PFA is a middle age patient affected by isolated, debilitating noninflammatory PFOA not responsive to conservative treatment and with normal limb alignment. ${ }^{4}$ The main indications and contraindications are summarized in -Table 1.

\section{Implant Design}

The first PFA design was an isolated resurfacing of the patella with a screw-on Vitallium patellar shell. Despite initial encouraging results, it was quickly abandoned due to excessive wear in the trochlear groove. ${ }^{16,30}$

The first generation of complete PFA (both sides) only replaced the trochlear cartilage leaving the subchondral bone intact (inlay design); so, the position of the PFA was related to the anatomy of the native trochlea. Furthermore, the trochlear component was positioned flush with the surrounding cartilage, the rotational alignment was parallel to the trochlear inclination, the mediolateral coverage was limited, and the surgical technique was mainly free hand. ${ }^{31}$ Firstgeneration PFA was successful in the short-term period, providing early pain relief, but the results were not maintained over time and more than $50 \%$ of the implants failed in the midto long-term follow-up with high reoperation rate. ${ }^{32}$

The second-generation PFA was designed to improve clinical outcomes and address the limitations of the previous design, mainly related to maltracking and instability. ${ }^{31}$ These implants used the same anterior femoral cuts as in TKA and completely replaced the anterior compartment of the knee (onlay design). Furthermore, these were characterized by a broad trochlear flange that narrowed distally, ${ }^{18}$ a valgus tracking angle and a good congruity throughout the entire ROM, avoiding catching, snapping, or popping. ${ }^{4}$

Both generations include symmetric and asymmetric implants. The second-generation designs can be used in all patients, regardless of anatomic variations, and are therefore more versatile and suitable. ${ }^{21}$

The PF implants can also be sorted according to the morphology of each component. The patellar button can be shaped with facets or as a dome and can be symmetric or asymmetric. It is advisable that patellar button design match the trochlear shape of TKAs to allow for retention of the component, if a PFA revision is required. ${ }^{33}$

Nevertheless, the evolution of PFA is mostly based on the design of the trochlear component. The sagittal radius of curvature, the mediolateral width, the distal-proximal extension, and the grade of constrain are the most important features of the trochlear design. ${ }^{34} \mathrm{~A}$ less constrained design allows the patella for more freedom but may increase the risk of patellar instability. On the contrary, a more constrained design (deep trochlear groove) allows less patellar movement causing an increase in PF loads and a high risk of early loosening. ${ }^{33}$ Consequently, the goal of implant design is to reproduce as close as possible the normal anatomy, thereby allowing smooth patellar tracking and minimizing the risk of subluxation or dislocation. ${ }^{34-36}$ The sagittal radius of curvature and the proximal extension of the implant determine the point of engagement of the patellar button with the trochlear component. $^{37}$ These parameters can significantly influence patellar tracking. Furthermore, the point at which the patellar button engages the trochlear component is also influenced by the distal coverage of the implant. ${ }^{33}$

Nowadays, inlay implants have been mostly abandoned and onlay implants are mainly used worldwide.

\section{Surgical Technique (Onlay Design)}

After a midline incision (from $1 \mathrm{~cm}$ proximal to the patella to just proximal to the tibial tubercle), the arthrotomy can be performed using surgeon's choice between medial parapatellar, midvastus, or subvastus approach. Care must be taken to avoid damaging the menisci, ligaments, or tibiofemoral articular cartilage. The patella can be either laterally dislocated or left in place and gently and partially everted. At this point, the surgeon should inspect the entire knee to confirm that the tibiofemoral joint is not involved and there are no ligamentous injuries.

The precise technique of implantation varies with the implant used. As a general rule, the trochlea is prepared with an anterior cutting guide, taking care not to damage the anterior cortex of the femur. ${ }^{33}$

Evaluation of the correct rotational alignment is mandatory to obtain good outcomes, and it can be achieved using an intramedullary femoral guide, navigation, or robotic devices. $^{38,39}$

The anterior femoral cut can be either performed in an "anatomical" or "functional" fashion. The "anatomical" anterior 
femoral cut is performed perpendicular to the AP axis (Whiteside's line) or parallel to the transepicondylar axis and then the patella is recentered by freeing up the lateral retinaculum. Alternatively, the "functional" femoral cut can be performed with more external rotation relative to the patellar plane and can be combined with lateral translation of the femoral component to avoid additional procedures on the extensor mechanism. $^{33}$

Once the appropriate rotation is obtained, the anterior cut is performed and the appropriate size of the trochlear component is selected. The presence of the "grand piano" is the sign of a good external rotation of the component. The sign is an image, resembling a grand piano, that results on the anterior cut of the femur as a consequence of the asymmetric anterior cut. ${ }^{11}$ To avoid maltracking, the cutting guide and then the definitive implant, should be placed slightly lateral. Once the femur has been prepared, the trial component is impacted to make sure there is no ACL impingement and no stepoff with the condylar cartilage.

The patellar cut is performed as in the standard TKA. It is important to leave at least $14 \mathrm{~mm}$ of bone thickness, and care must be taken to avoid asymmetric cut and overstuffed component. If it is not possible to leave an adequate amount of bone stock, a bone graft, and cement or patella augmentation button are viable solutions. ${ }^{40}$ To prevent maltracking, the patellar component should be medialized and the lateral osteophytes should be removed to avoid bony impingement. ${ }^{11}$

The patella tracking should be carefully checked with trial components. If it is not adequate, a lateral release can be performed. In case of more severe malalignment, advancement of the vastus medialis or tibial tubercle transfer can be performed. However, these procedures should be carefully planned preoperatively, and worse outcomes can be expected. ${ }^{33,40}$ When the correct size and position of the implant are achieved, the trial components are removed and the definitive components are cemented. Surgeons should be careful to avoid thermal damage to the adjacent cartilage during cementation (-Fig. 1).

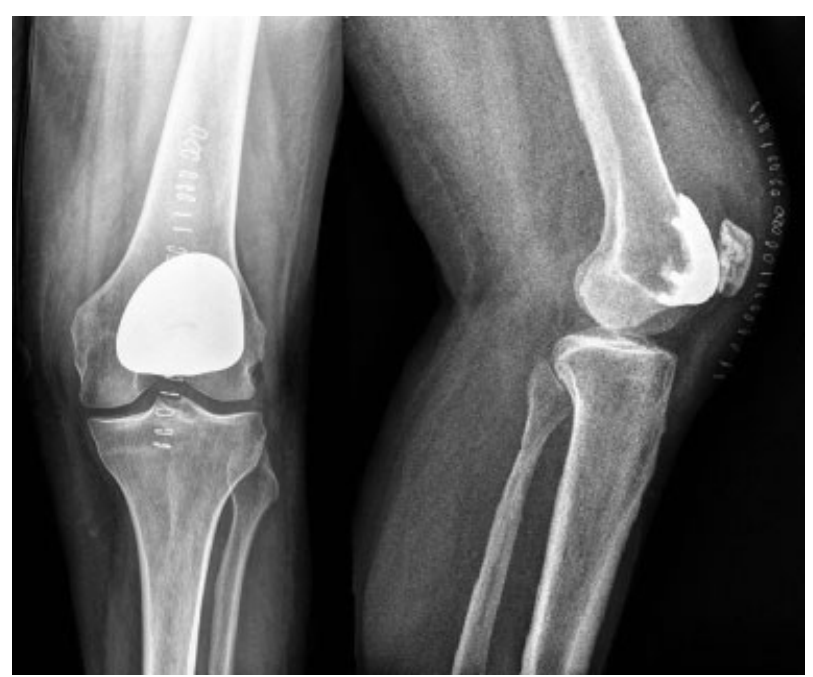

Fig. 1 Anteroposterior and lateral X-ray view after left PFA implants. PFA, patellofemoral arthroplasty.

\section{Postoperative Rehabilitation}

Postoperative care follows the same indications as in the TKA. Full weight bearing is immediately allowed as tolerated. Rehabilitation focuses on active and passive ROM exercises along with gait training. In case of additional procedures, such as advancement of the vastus medialis oblique or tibial tubercle transfer, a slower and more cautious rehabilitation may be required. ${ }^{11,40}$

\section{Complications and Failure}

PFA shares most of the complications with the TKA, such as polyethylene wear, arthrofibrosis, and persistent pain. Early complications, such as persistent anterior knee pain, patellar catching or snapping, intraoperative fracture, and extensor mechanism failure are more frequent in PFA than in TKA and are mostly related to malpositioning. ${ }^{41,42}$ Conversely, loosening and infection occur at a lower rate compared with TKA. ${ }^{43,44}$ However, there are some specific early complications related to PFA that should be mentioned. One specific complication is a lateral swelling due to a hematoma after bleeding in the lateral compartment when a lateral release during PFA is performed. Another common complication is patellar maltracking or patellar instability due to failure of a medial ligament repair or an inadequate tracking correction during surgery. Furthermore, peripatellar pain due to "overstuffing" of the patellar component can occur. Another specific complication is lateral catching due to wrong realignment of the extensor mechanism, or more frequently, to poor trochlear component placement, frequently related to a rotational malposition. ${ }^{45}$

Late complications requiring revision usually occur in the setting of a well-functioning PFA. The most common cause of late PFA failure is progression of tibiofemoral OA, accounting for approximately $25 \%$ of the revision at 15 years of follow-up. ${ }^{46,47}$ Some authors reported that tibiofemoral OA progression is more frequent in obese patients and when the indication is primary PFOA compared with those affected by trochlear dysplasia. ${ }^{10,46-50}$ Aseptic loosening is another possible cause of revision and is more frequent in cementless PFA. ${ }^{10}$ Van der List et $\mathrm{al}^{42}$ published a systematic review, including 39 studies evaluating failures after PFA. The authors concluded that the first cause of failure was tibiofemoral OA progression (38\%), pain (16\%), aseptic loosening (14\%), and patellar maltracking (10\%). Furthermore, pain was recognized as the first cause (31\%) of early failures (within 5 years), while OA progression was more common in late failures (46\%).

\section{Results: Literature Review}

The outcomes for PFA were quite variable, mainly because of the improvement in surgical technique, patient selection, and implant design. ${ }^{51}$ A recent systematic review published by van der List et $\mathrm{al}^{42}$ concluded that the survivorship of PFA at 5-, 10-, 15-, and 20-year follow-up was 91.7, 83.3, 74.9, and $66.6 \%$, respectively. There were few studies comparing inlay and onlay PFA. Van der List et $\mathrm{al}^{42}$ found that studies published before 2010 reported a higher annual revision rate when compared with more recently published studies 
(2.33 vs. 1.93). Furthermore, the authors reported good to excellent results in $87.3 \%$ of the patients 5 years after surgery. Similar to other studies, the authors concluded that better long-term outcomes and survivorship could be expected with second-generation implants. ${ }^{42,44}$

Dy et $\mathrm{al}^{44}$ performed a meta-analysis to compare complication, reoperation, and revision rate following first- and secondgeneration PFA and between PFA versus TKA for PFOA. The authors concluded that there was a higher risk of reoperation (OR: 4.33) and revision (OR: 4.93) in first generation compared with second-generation PFA. ${ }^{44}$

\section{Inlay PFA}

Tauro et $\mathrm{al}^{32}$ reviewed 66 inlay PFAs with $65 \%$ of survivorship rate at 8 -year follow-up and only $45 \%$ of good or excellent results. The most frequent cause of revision was patellar maltracking and progression of tibiofemoral OA. Argenson et $\mathrm{al}^{10}$ reported $58 \%$ survival at 16 -year follow-up, while Van Jonbergen et $\mathrm{al}^{27}$ reported $69 \%$ survivorship at 20 -year follow-up. However, also in these studies, the main reasons for revision were progression of tibiofemoral $\mathrm{OA}$ and patellofemoral complications. Other authors described an incidence of patellar maltracking after inlay PFA ranged between 17 and 36\%. 17,32,35,52 The Australian National Joint Replacement Registry reported that more than $20 \%$ of the implants needed a revision at 5 -year follow-up. ${ }^{53}$ All the studies are summarized in - Table 2 . In summary, results with the first generation of PFA have been disappointing, with high complication and failure rates. ${ }^{33}$

\section{Onlay PFA}

The second-generation PFA demonstrated significantly improved short- and mid-term outcomes due to a careful patient selection. The Australian National Joint Replacement Registry reported less than $10 \%$ revision rates for onlay PFAs. ${ }^{53}$ The onlay design could reduce the incidence of patellar maltracking to $1 \%$ after PFA. ${ }^{49,54-56}$ Therefore, when patellar tracking was satisfactory after PFA, revisions due to patellofemoral issues were reduced, leaving progression of tibiofemoral $\mathrm{OA}$ as the first cause of failure. Excellent results were reported by Ackroyd et a ${ }^{54}$ with a 5 -year survivorship of $96 \%$. Sisto et al, ${ }^{57}$ in a series of custom-made implants, reported $100 \%$ survivorship at 6 years with good to excellent results in all the patients. Also,

Table 2 PFA inlay design results

\begin{tabular}{|c|c|c|c|c|c|}
\hline Author & $\begin{array}{l}N \text { cases } \\
\text { (mean age) }\end{array}$ & Prosthesis design & $\begin{array}{l}\text { Follow-up } \\
\text { (y) }\end{array}$ & $\begin{array}{l}\text { Revision } \\
\text { rate (\%) }\end{array}$ & $\begin{array}{l}\text { Good or excellent } \\
\text { results (\%) }\end{array}$ \\
\hline Blazina et al ${ }^{17}$ & $57(39)$ & Richards I \& II & 2 & 35 & $\mathrm{~N} / \mathrm{A}$ \\
\hline Arciero et al ${ }^{24}$ & $25(62)$ & Richards IICFS-Wright & 5.3 & 28 & 85 \\
\hline Cartier et al ${ }^{72}$ & $72(65)$ & Richards I \& II & 4 & 7 & 85 \\
\hline Argenson et al ${ }^{10}$ & $66(57)$ & Autocentric & 5.5 & 15 & 84 \\
\hline Krajca-Radcliffe and Coker ${ }^{46}$ & $16(64)$ & Richards I \& II & 5.8 & 6 & 88 \\
\hline Mertl et a ${ }^{73}$ & $51(60)$ & Spherocentric & 3 & 6 & 82 \\
\hline Arnbjörnsson and $\mathrm{Ryd}^{74}$ & $113(56)$ & Multiple & 7 & 22 & 75 \\
\hline De Cloedt et al ${ }^{75}$ & $45(51)$ & Autocentric & 6 & 18 & 63 \\
\hline de Winter et al ${ }^{52}$ & $26(59)$ & Richards II & 11 & 19 & 76 \\
\hline Tauro et $\mathrm{al}^{32}$ & $62(66)$ & Lubinus & 7.5 & 28 & 45 \\
\hline Smith et a ${ }^{76}$ & $45(72)$ & Lubinus & 4 & 19 & 64 \\
\hline Kooijman et al $^{47}$ & $45(50)$ & Richards II & 17 & 22 & 86 \\
\hline Board et al ${ }^{77}$ & $17(66)$ & Lubinus & 1.5 & 35 & 53 \\
\hline Lonner $^{35}$ & $30(38)$ & Lubinus & 4 & 33 & 84 \\
\hline Merchant $^{78}$ & $16(47)$ & LCS & 4.5 & 0 & 94 \\
\hline Argenson et al ${ }^{79}$ & $66(57)$ & Autocentric & 16.2 & 42 & 84 \\
\hline Cartier et al ${ }^{36}$ & $79(60)$ & Richards II \& III & 10 & 25 & 77 \\
\hline Sisto and Sarin ${ }^{57}$ & $25(45)$ & Kinematch & 6 & 0 & 100 \\
\hline Jørgensen et al ${ }^{80}$ & $31(\mathrm{~N} / \mathrm{A})$ & Richards II & 7.7 & 3 & 65 \\
\hline Gadeyne et al ${ }^{81}$ & $43(67)$ & Autocentric & 6 & 24 & 72 \\
\hline van Wagenberg et al ${ }^{48}$ & $24(64)$ & Autocentric & 4.8 & 29 & 30 \\
\hline van Jonbergen et al ${ }^{27}$ & $185(52)$ & Richards II & 13.3 & 25 & 84 \\
\hline Charalambous et al $^{82}$ & $51(64)$ & LCS & 2 & 33 & 33 \\
\hline Hoogervorst et $\mathrm{al}^{83}$ & $33(47)$ & Richards II & 9.7 & 21 & 90 \\
\hline
\end{tabular}

Abbreviations: LCS, low contact stress; N, number; PFA, patellofemoral arthroplasty. 
Butler et $\mathrm{al}^{58}$ in a smaller series of custom-made implants, reported $91 \%$ survivorship at 5-year follow-up. Leadbetter et $\mathrm{al}^{49}$ in a series of 79 onlay PFAs, reported $94 \%$ survivorship at a mean 3-year follow-up with $84 \%$ good to excellent results. Similar results were reported by other authors at 5-year followup despite a $26 \%$ reoperation rate for lateral release, debridement, tibial tubercle transfer, or arthroscopic assessment. ${ }^{59}$ All the studies are summarized in - Table 3.

\section{Patellofemoral Arthroplasty versus Total Knee Arthroplasty}

Several studies reported successful results after TKA for isolated PFOA with good mid-term results in approximately $90 \%$ of patients. However, almost $19 \%$ of the patients still experienced anterior knee pain after surgery. ${ }^{60-62}$ Dahm et $\mathrm{al}^{41}$ compared 33 patients who underwent PFA versus 22 patients who underwent TKA for isolated PFOA with 2.5-year followup. The group reported similar functional and pain scores but higher activity scores in the PFA group. Furthermore, PFA group had fewer complications, shorter postoperative hospital stays, less blood loss, and a better postoperative flexion (127 vs. 118 degrees). Dy et $\mathrm{al}^{44}$ in a meta-analysis, compared the mid-term results and complications of PFA (inlay and onlay) versus TKA. The authors concluded higher reoperation and revision rates (odds ratio $[O R]=8.06$ and 8.11 , respectively) for PFA compared with TKA. However, when first- and secondgeneration PFA were grouped separately, first-generation PFA demonstrated a higher reoperation and revision rate (OR $=4.33$ and 4.39 , respectively) compared with second-generation PFA, and there were no differences between secondgeneration PFA and TKA regarding reoperation or revision rate, pain, or mechanical complications. ${ }^{44}$ Lonner et al ${ }^{63}$ and van Jonbergen et $\mathrm{al}^{64}$ compared the outcomes of TKA after failed PFA to primary TKA. The studies reported similar outcomes in both the groups, and no significant technical problems were described in TKA after PFA. These findings were also confirmed by other studies. Several authors confirmed that PFA could potentially delay TKA, by 10 to 15 years in up to $80 \%$ of the patients, and revision to TKA can be performed without difficulty. ${ }^{15,41,50,54,63-65}$

Table 3 PFA onlay design results

\begin{tabular}{|c|c|c|c|c|c|}
\hline Author & $\begin{array}{l}N \text { cases } \\
\text { (mean age) }\end{array}$ & Prosthesis design & $\begin{array}{l}\text { Follow-up } \\
\text { (y) }\end{array}$ & $\begin{array}{l}\text { Revision } \\
\text { rate (\%) }\end{array}$ & $\begin{array}{l}\text { Good or excellent } \\
\text { results (\%) }\end{array}$ \\
\hline Lonner $^{35}$ & $25(44)$ & Avon & 0.5 & 0 & 96 \\
\hline Ackroyd and Chir $^{18}$ & $306(62)$ & Avon & 2 & 3.6 & 80 \\
\hline Cossey and Spriggins ${ }^{39}$ & $4(52)$ & Avon (Navigation) & 1 & 0 & 100 \\
\hline Nicol et al ${ }^{50}$ & $103(68)$ & Avon & 7.1 & 14 & $\mathrm{~N} / \mathrm{A}$ \\
\hline Ackroyd et $\mathrm{al}^{54}$ & $109(68)$ & Avon & 5.2 & 15 & 80 \\
\hline Mohammed et al ${ }^{59}$ & $101(57)$ & Multiple & 4 & 4 & 72 \\
\hline Butler and Shannon ${ }^{58}$ & $22(49)$ & Performa & 5 & 14 & $\mathrm{~N} / \mathrm{A}$ \\
\hline Leadbetter et al ${ }^{49}$ & $79(58)$ & Avon & 3 & 16 & 84 \\
\hline Starks et a ${ }^{55}$ & $37(66)$ & Avon & 2 & 0 & 86 \\
\hline Odumenya et a $\mathrm{a}^{37}$ & $50(66)$ & Avon & 5.3 & 4 & 94 \\
\hline Gao et $\mathrm{al}^{84}$ & $11(54)$ & Avon & 2 & 0 & 100 \\
\hline Sarda et al ${ }^{85}$ & $44(62)$ & Avon & 4.5 & 5 & 85 \\
\hline Mont et al ${ }^{56}$ & $43(49)$ & Avon & 7 & 12 & $\mathrm{~N} / \mathrm{A}$ \\
\hline Beitzel et al ${ }^{86}$ & $22(46)$ & Journey & 2 & 0 & $\mathrm{~N} / \mathrm{A}$ \\
\hline Yadav et al ${ }^{87}$ & $51(54)$ & LCS & 4.2 & 20 & $\mathrm{~N} / \mathrm{A}$ \\
\hline Davies et al ${ }^{88}$ & $52(61)$ & FPV & 2 & 13 & 79 \\
\hline Hofmann et al ${ }^{89}$ & $40(61)$ & Natural Knee II & 2.5 & 10 & 95 \\
\hline Morris et a ${ }^{90}$ & $31(55)$ & Multiple & 2.5 & 3 & $\mathrm{~N} / \mathrm{A}$ \\
\hline Williams et $\mathrm{al}^{91}$ & $48(63)$ & FPV & 2 & 15 & $\mathrm{~N} / \mathrm{A}$ \\
\hline Al-Hadity et al ${ }^{92}$ & $53(62)$ & FPV & 3 & 3 & 97 \\
\hline Benazzo et al $^{93}$ & $25(67)$ & Multiple & 4.7 & 12 & $\mathrm{~N} / \mathrm{A}$ \\
\hline Dahm et a $a^{94}$ & $59(56)$ & Avon & 4 & 3 & $\mathrm{~N} / \mathrm{A}$ \\
\hline Fink et $\mathrm{al}^{95}$ & $53(61)$ & Vanguard & 3.7 & 6 & $\mathrm{~N} / \mathrm{A}$ \\
\hline Hernigou et al ${ }^{96}$ & $85(71)$ & Hermes & 12 & 5 & 82 \\
\hline Akhbari et al ${ }^{97}$ & $61(66)$ & Avon & 5 & 7 & 80 \\
\hline Liow et $\mathrm{al}^{98}$ & $51(53)$ & Sigma & 4 & 8 & 76 \\
\hline
\end{tabular}

Abbreviations: FPV, Femoro Patella Vialla; LCS, low contact stress; N, number; PFA, patellofemoral arthroplasty; N/A, not available. 


\section{Patellofemoral Arthroplasty and Unicompartmental Knee Arthroplasty}

Currently, the association of PFA and UKA is one of the most debated topics. Traditionally, PFA was contraindicated in patients with evidence of tibiofemoral OA. Nowadays, with recent implant design and improvement in surgical techniques, combined PFA and medial or lateral tibiofemoral UKA can be performed with good results. ${ }^{66,67}$ Furthermore, the possibility to perform a UKA in cases of failure of PFA due to medial or lateral tibiofemoral OA progression may avoid the revision to TKA. ${ }^{33}$ Indeed, the association between PFA and UKA allows for retaining of the medial pivot, with consequent better knee kinematic. ${ }^{68}$ This procedure can be performed in young patients or in elderly patients with severe comorbidities because of the less invasiveness of the surgery compared with TKA. ${ }^{23}$ Some authors have described promising results for PFA associated to UKA. Argenson et $\mathrm{al}^{67}$ reported optimal ROM and no postoperative pain in 17 patients treated with unlinked PFA and UKA. Heyse et $\mathrm{al}^{69}$ reported a $100 \%$ survivorship at 12 -year follow-up in nine patients treated with UKA and PFA. Kamath et al ${ }^{70}$ described an improvement in all 21 patients treated with PFA and UKA at 2-year follow-up and reported only one significant complication (knee instability). Parratte et al ${ }^{71}$ reported a $54 \%$ survivorship at 17-year follow-up in 77 knees with a good satisfaction rate. Also, Sabatini et al ${ }^{23}$ reported an improvement in functional and clinical scores at 18-month follow-up in a case series of six knees treated with isolated PFA and nine knees treated with combined PFA and UKA. However, few studies are available that have evaluated the association of PFA and UKA, with small numbers and short follow-ups.

\section{Conclusion}

PFA has shown to be a viable option for the treatment of isolated PFOA. The ideal candidate for a PFA is a middle-aged female with PFOA not responsive to the conservative treatment and without significant malalignment or tibiofemoral OA. Modern PFA design onlay style, strict patient selection, and improvement in surgical techniques have produced satisfactory results in the past decades in short- to mid-term follow-up, with 10years of survivorship of almost $90 \%$. The main cause of failure of second-generation PFA is progression of tibiofemoral OA. However, the introduction of the association of PFA and UKA may reduce the need for revision to TKA due to tibiofemoral OA progression. Despite the good mid-term outcomes after PFA, future research is warranted to evaluate the long-term results of the second-generation PFA, and eventually, the efficacy of combination of PFA and UKA in comparison with TKA.

\section{References}

1 Duncan R, Peat G, Thomas E, Wood L, Hay E, Croft P. Does isolated patellofemoral osteoarthritis matter? Osteoarthritis Cartilage 2009;17(09):1151-1155

2 Lüring C, Tingart M, Drescher W, Springorum HR, Kraft CN, Rath B. Therapy of isolated arthritis in the patellofemoral joint: are there evidence-based options? [Article in German]. Orthopade 2011;40 (10):902-906
3 McAlindon TE, Snow S, Cooper C, Dieppe PA. Radiographic patterns of osteoarthritis of the knee joint in the community: the importance of the patellofemoral joint. Ann Rheum Dis 1992;51 (07):844-849

4 Walker T, Perkinson B, Mihalko WM. Patellofemoral arthroplasty: the other unicompartmental knee replacement. J Bone Joint Surg Am 2012;94(18):1712-1720

5 Lonner JH. Patellofemoral arthroplasty. J Am Acad Orthop Surg 2007;15(08):495-506

6 Kobayashi S, Pappas E, Fransen M, Refshauge K, Simic M. The prevalence of patellofemoral osteoarthritis: a systematic review and meta-analysis. Osteoarthritis Cartilage 2016;24(10):1697-1707

7 Mills K, Hunter DJ. Patellofemoral joint osteoarthritis: an individualised pathomechanical approach to management. Best Pract Res Clin Rheumatol 2014;28(01):73-91

8 Grelsamer RP, Stein DA. Patellofemoral arthritis. J Bone Joint Surg Am 2006;88(08):1849-1860

9 Cooper C, McAlindon T, Snow S, et al. Mechanical and constitutional risk factors for symptomatic knee osteoarthritis: differences between medial tibiofemoral and patellofemoral disease. J Rheumatol 1994;21(02):307-313

10 Argenson JN, Guillaume JM, Aubaniac JM. Is there a place for patellofemoral arthroplasty? Clin Orthop Relat Res 1995;(321): 162-167

11 Oni JK, Hochfelder J, Dayan A. Isolated patellofemoral arthroplasty. Bull Hosp Jt Dis (2013) 2014;72(01):97-103

12 Culvenor AG, Cook JL, Collins NJ, Crossley KM. Is patellofemoral joint osteoarthritis an under-recognised outcome of anterior cruciate ligament reconstruction? A narrative literature review. Br J Sports Med 2013;47(02):66-70

13 Minkowitz RB, Bosco JA III. Patellofemoral arthritis. Bull NYU Hosp Jt Dis 2009;67(01):30-38

14 van Jonbergen HP, Poolman RW, van Kampen A. Isolated patellofemoral osteoarthritis. Acta Orthop 2010;81(02):199-205

15 Gupta RR, Zywiel MG, Leadbetter WB, Bonutti P, Mont MA. Scientific evidence for the use of modern patellofemoral arthroplasty. Expert Rev Med Devices 2010;7(01):51-66

16 Levitt RL. A long-term evaluation of patellar prostheses. Clin Orthop Relat Res 1973;(97):153-157

17 Blazina ME, Fox JM, Del Pizzo W, Broukhim B, Ivey FM. Patellofemoral replacement. Clin Orthop Relat Res 1979;(144):98-102

18 Ackroyd CE, Chir B. Development and early results of a new patellofemoral arthroplasty. Clin Orthop Relat Res 2005;(436):7-13

19 Senavongse W, Amis AA. The effects of articular, retinacular, or muscular deficiencies on patellofemoral joint stability: a biomechanical study in vitro. J Bone Joint Surg Br 2005;87(04):577-582

20 Rauh MA, Parker RD. Patella. In: Miller MD, Thompson SR, eds. DeLee \& Drez's Orthopaedic Sports Medicine. 3rd ed. Philadelphia: Saunders; 2009

21 Lonner JH, Bloomfield MR. The clinical outcome of patellofemoral arthroplasty. Orthop Clin North Am 2013;44(03):271-280, vii

22 IwanoT, Kurasawa H, Tokuyama H, Hoshikawa Y. Roentgenographic and clinical findings of patellofemoral osteoarthrosis. With special reference to its relationship to femorotibial osteoarthrosis and etiologic factors. Clin Orthop Relat Res 1990;(252):190-197

23 Sabatini L, Schirò M, Atzori F, Ferrero G, Massè A. Patellofemoral Joint Arthroplasty: our experience in isolated patellofemoral and bicompartmental arthritic knees. Clin Med Insights Arthritis Musculoskelet Disord 2016;9:189-193

24 Arciero RA, Toomey HE. Patellofemoral arthroplasty. A three- to nine-year follow-up study. Clin Orthop Relat Res 1988;(236): 60-71

25 Leadbetter WB, Seyler TM, Ragland PS, Mont MA. Indications, contraindications, and pitfalls of patellofemoral arthroplasty. J Bone Joint Surg Am 2006;88(Suppl 4):122-137

26 Dejour DH. The patellofemoral joint and its historical roots: the Lyon School of Knee Surgery. Knee Surg Sports Traumatol Arthrosc 2013;21(07):1482-1494 
27 van Jonbergen HP, Werkman DM, Barnaart LF, van Kampen A. Long-term outcomes of patellofemoral arthroplasty. J Arthroplasty 2010;25(07):1066-1071

28 Leadbetter WB, Ragland PS, Mont MA. The appropriate use of patellofemoral arthroplasty: an analysis of reported indications, contraindications, and failures. Clin Orthop Relat Res 2005;(436): 91-99

29 Delanois RE, McGrath MS, Ulrich SD, et al. Results of total knee replacement for isolated patellofemoral arthritis: when not to perform a patellofemoral arthroplasty. Orthop Clin North Am 2008;39(03):381-388, vii

30 Vermeulen H, De Doncker E, Watillon M. The Mac Keever patellar prosthesis in femoro-patellar arthrosis [Article in French]. Acta Orthop Belg 1973;39(01):79-90

31 Borus T, Brilhault J, Confalonieri N, Johnson D, Thienpont E. Patellofemoral joint replacement, an evolving concept. Knee 2014;21(Suppl 1):S47-S50

32 Tauro B, Ackroyd CE, Newman JH, Shah NA. The Lubinus patellofemoral arthroplasty. A five- to ten-year prospective study. J Bone Joint Surg Br 2001;83(05):696-701

33 Lustig S. Patellofemoral arthroplasty. Orthop Traumatol Surg Res 2014;100(1, Suppl)S35-S43

34 Lonner JH. Patellofemoral arthroplasty: the impact of design on outcomes. Orthop Clin North Am 2008;39(03):347-354, vi

35 Lonner JH. Patellofemoral arthroplasty: pros, cons, and design considerations. Clin Orthop Relat Res 2004;(428):158-165

36 Cartier P, Sanouiller JL, Khefacha A. Long-term results with the first patellofemoral prosthesis. Clin Orthop Relat Res 2005;(436): 47-54

37 Odumenya M, Costa ML, Parsons N, Achten J, Dhillon M, Krikler SJ. The Avon patellofemoral joint replacement: five-year results from an independent centre. J Bone Joint Surg $\mathrm{Br}$ 2010;92(01):56-60

38 Shakespeare D, Dikko B. A simple precise technique for making the anterior cut in patellofemoral resurfacing. Knee 2005;12(06): 454-455

39 Cossey AJ, Spriggins AJ. Computer-assisted patellofemoral arthroplasty: a mechanism for optimizing rotation. J Arthroplasty 2006; 21(03):420-427

40 Newman J. Isolated patellofemoral replacement. In: Romagnoli S, Confalonieri N, eds. Small Implants in the Knee Reconstruction. Italia: Springer-Verlag; 2013

41 Dahm DL, Al-Rayashi W, Dajani K, Shah JP, Levy BA, Stuart MJ. Patellofemoral arthroplasty versus total knee arthroplasty in patients with isolated patellofemoral osteoarthritis. Am J Orthop 2010;39(10):487-491

42 van der List JP, Chawla H, Villa JC, Pearle AD. Why do patellofemoral arthroplasties fail today? A systematic review. Knee 2017; 24(01):2-8

43 Amanatullah DF, Jamali AA. Patellar polyethylene spinout after low-contact stress, high-congruity, mobile-bearing patellofemoral arthroplasty. Orthopedics 2012;35(02):e272-e276

44 Dy CJ, Franco N, Ma Y, Mazumdar M, McCarthy MM, Gonzalez Della Valle A. Complications after patello-femoral versus total knee replacement in the treatment of isolated patello-femoral osteoarthritis. A meta-analysis. Knee Surg Sports Traumatol Arthrosc 2012;20(11):2174-2190

45 Mulford JS, Eldridge JD, Porteous AJ, Ackroyd CE, Newman JH. Revision of isolated patellofemoral arthroplasty to total knee replacement. Curr Orthop Pract 2009;20(04):437-441

46 Krajca-Radcliffe JB, Coker TP. Patellofemoral arthroplasty. A 2- to 18-year followup study. Clin Orthop Relat Res 1996;(330): 143-151

47 Kooijman HJ, Driessen AP, van Horn JR. Long-term results of patellofemoral arthroplasty. A report of 56 arthroplasties with 17 years of follow-up. J Bone Joint Surg Br 2003;85(06):836-840

48 van Wagenberg JM, Speigner B, Gosens T, de Waal Malefijt J. Midterm clinical results of the Autocentric II patellofemoral prosthesis. Int Orthop 2009;33(06):1603-1608
49 Leadbetter WB, Kolisek FR, Levitt RL, et al. Patellofemoral arthroplasty: a multi-centre study with minimum 2-year follow-up. Int Orthop 2009;33(06):1597-1601

50 Nicol SG, Loveridge JM, Weale AE, Ackroyd CE, Newman JH. Arthritis progression after patellofemoral joint replacement. Knee 2006;13(04):290-295

51 Lonner JH. Patellofemoral arthroplasty. Instr Course Lect 2010; 59:67-84

52 de Winter WE, Feith R, van Loon CJ. The Richards type II patellofemoral arthroplasty: 26 cases followed for 1-20 years. Acta Orthop Scand 2001;72(05):487-490

53 Registry Australian Oarthopaedic Association National Joint Replacement. Available at: https://aoanjrr.sahmri.com. Accessed 2016

54 Ackroyd CE, Newman JH, Evans R, Eldridge JD, Joslin CC. The Avon patellofemoral arthroplasty: five-year survivorship and functional results. J Bone Joint Surg Br 2007;89(03):310-315

55 Starks I, Roberts S, White SH. The Avon patellofemoral joint replacement: independent assessment of early functional outcomes. J Bone Joint Surg Br 2009;91(12):1579-1582

56 Mont MA, Johnson AJ, Naziri Q, Kolisek FR, Leadbetter WB. Patellofemoral arthroplasty: 7-year mean follow-up. J Arthroplasty 2012;27(03):358-361

57 Sisto DJ, Sarin VK. Custom patellofemoral arthroplasty of the knee. J Bone Joint Surg Am 2006;88(07):1475-1480

58 Butler JE, Shannon R. Patellofemoral arthroplasty with a customfit femoral prosthesis. Orthopedics 2009;32(02):81

59 Mohammed R, Jimulia T, Durve K, Bansal M, Green M, Learmonth D. Medium-term results of patellofemoral joint arthroplasty. Acta Orthop Belg 2008;74(04):472-477

60 Parvizi J, Stuart MJ, Pagnano MW, Hanssen AD. Total knee arthroplasty in patients with isolated patellofemoral arthritis. Clin Orthop Relat Res 2001;(392):147-152

61 Laskin RS, van Steijn M. Total knee replacement for patients with patellofemoral arthritis. Clin Orthop Relat Res 1999;(367): 89-95

62 Mont MA, Haas S, Mullick T, Hungerford DS. Total knee arthroplasty for patellofemoral arthritis. J Bone Joint Surg Am 2002; 84-A(11):1977-1981

63 Lonner JH, Jasko JG, Booth RE Jr. Revision of a failed patellofemoral arthroplasty to a total knee arthroplasty. J Bone Joint Surg Am 2006;88(11):2337-2342

64 van Jonbergen HP, Werkman DM, van Kampen A. Conversion of patellofemoral arthroplasty to total knee arthroplasty: a matched case-control study of 13 patients. Acta Orthop 2009;80(01): 62-66

65 Leadbetter WB. Patellofemoral arthroplasty in the treatment of patellofemoral arthritis: rationale and outcomes in younger patients. Orthop Clin North Am 2008;39(03):363-380, vii

66 Lonner JH. Modular bicompartmental knee arthroplasty with robotic arm assistance. Am J Orthop 2009;38(2, Suppl)28-31

67 Argenson JN, Parratte S, Bertani A, et al. The new arthritic patient and arthroplasty treatment options. J Bone Joint Surg Am 2009;91 (Suppl 5):43-48

68 Leffler J, Scheys L, Planté-Bordeneuve T, et al. Joint kinematics following bi-compartmental knee replacement during daily life motor tasks. Gait Posture 2012;36(03):454-460

69 Heyse TJ, Khefacha A, Cartier P. UKA in combination with PFR at average 12-year follow-up. Arch Orthop Trauma Surg 2010;130 (10):1227-1230

70 Kamath AF, Levack A, John T, Thomas BS, Lonner JH. Minimum two-year outcomes of modular bicompartmental knee arthroplasty. J Arthroplasty 2014;29(01):75-79

71 Parratte S, Ollivier M, Lunebourg A, Abdel MP, Argenson JN. Longterm results of compartmental arthroplasties of the knee: Long term results of partial knee arthroplasty. Bone Joint J 2015;97-B (10, Suppl A)9-15

72 Cartier P, Sanouiller JL, Grelsamer R. Patellofemoral arthroplasty. 2-12-year follow-up study. J Arthroplasty 1990;5(01):49-55 
73 Mertl P, Van FT, Bonhomme P, Vives P. Femoropatellar osteoarthritis treated by prosthesis. Retrospective study of 50 implants [Article in French]. Rev Chir Orthop Repar Appar Mot 1997;83 (08):712-718

74 Arnbjörnsson AH, Ryd L. The use of isolated patellar prostheses in Sweden 1977-1986. Int Orthop 1998;22(03):141-144

75 De Cloedt P, Legaye J, Lokietek W. Femoro-patellar prosthesis. A retrospective study of 45 consecutive cases with a follow-up of 3-12 years [Article in French]. Acta Orthop Belg 1999;65(02): 170-175

76 Smith AM, Peckett WR, Butler-Manuel PA, Venu KM, d'Arcy JC. Treatment of patello-femoral arthritis using the Lubinus patellofemoral arthroplasty: a retrospective review. Knee 2002;9(01): 27-30

77 Board TN, Mahmood A, Ryan WG, Banks AJ. The Lubinus patellofemoral arthroplasty: a series of 17 cases. Arch Orthop Trauma Surg 2004;124(05):285-287

78 Merchant AC. A modular prosthesis for patellofemoral arthroplasty: design and initial results. Clin Orthop Relat Res 2005; (436):40-46

79 Argenson JN, Flecher X, Parratte S, Aubaniac JM. Patellofemoral arthroplasty: an update. Clin Orthop Relat Res 2005;440(440): 50-53

80 Jørgensen PS, Konradsen LA, Mati WB, Tørholm C. Treatment of patellofemoral arthritis with patello-femoral arthroplasties [Article in Danish]. Ugeskr Laeger 2007;169(23):2201-2204

81 Gadeyne S, Besse JL, Galand-Desme S, Lerat JL, Moyen B. Results of self-centering patellofemoral prosthesis: a retrospective study of 57 implants [Article in French]. Rev Chir Orthop Repar Appar Mot 2008;94(03):228-240

82 Charalambous CP, Abiddin Z, Mills SP, Rogers S, Sutton P, Parkinson $\mathrm{R}$. The low contact stress patellofemoral replacement: high early failure rate. J Bone Joint Surg Br 2011;93(04):484-489

83 Hoogervorst P, de Jong RJ, Hannink G, van Kampen A. A 21\% conversion rate to total knee arthroplasty of a first-generation patellofemoral prosthesis at a mean follow-up of 9.7 years. Int Orthop 2015;39(09):1857-1864

84 Gao X, Xu ZJ, He RX, Yan SG, Wu LD. A preliminary report of patellofemoral arthroplasty in isolated patellofemoral arthritis. Chin Med J (Engl) 2010;123(21):3020-3023

85 Sarda PK, Shetty A, Maheswaran SS. Medium term results of Avon patellofemoral joint replacement. Indian J Orthop 2011;45(05): 439-444
86 Beitzel K, Schöttle PB, Cotic M, Dharmesh V, Imhoff AB. Prospective clinical and radiological two-year results after patellofemoral arthroplasty using an implant with an asymmetric trochlea design. Knee Surg Sports Traumatol Arthrosc 2013;21(02):332-339

87 Yadav B, Shaw D, Radcliffe G, Dachepalli S, Kluge W. Mobilebearing, congruent patellofemoral prosthesis: short-term results. J Orthop Surg (Hong Kong) 2012;20(03):348-352

88 Davies AP. High early revision rate with the FPV patello-femoral unicompartmental arthroplasty. Knee 2013;20(06):482-484

89 Hofmann AA, McCandless JB, Shaeffer JF, Magee TH. Patellofemoral replacement: the third compartment. Bone Joint J 2013;95B(11, Suppl A)124-128

90 Morris MJ, Lombardi AV Jr, Berend KR, Hurst JM, Adams JB. Clinical results of patellofemoral arthroplasty. J Arthroplasty 2013;28(9, Suppl)199-201

91 Williams DP, Pandit HG, Athanasou NA, Murray DW, Gibbons CL. Early revisions of the Femoro-Patella Vialla joint replacement. Bone Joint J 2013;95-B(06):793-797

92 Al-Hadithy N, Patel R, Navadgi B, Deo S, Hollinghurst D, Satish V. Mid-term results of the FPV patellofemoral joint replacement. Knee 2014;21(01):138-141

93 Benazzo F, Rossi SM, Ghiara M. Partial knee arthroplasty: patellofemoral arthroplasty and combined unicompartmental and patellofemoral arthroplasty implants-general considerations and indications, technique and clinical experience. Knee 2014; 21(Suppl 1):S43-S46

94 Dahm DL, Kalisvaart MM, Stuart MJ, Slettedahl SW. Patellofemoral arthroplasty: outcomes and factors associated with early progression of tibiofemoral arthritis. Knee Surg Sports Traumatol Arthrosc 2014;22(10):2554-2559

95 Fink B, Schwenninger C. Arthroplasty of the Femoropatellar JointWhat Data are Available? [Article in German]. Z Orthop Unfall 2014;152(02):182-187

96 Hernigou P, Caton J. Design, operative technique and ten-year results of the Hermes ${ }^{\mathrm{TM}}$ patellofemoral arthroplasty. Int Orthop 2014;38(02):437-442

97 Akhbari P, Malak T, Dawson-Bowling S, East D, Miles K, ButlerManuel PA. The avon patellofemoral joint replacement: mid-term prospective results from an independent centre. Clin Orthop Surg 2015;7(02):171-176

98 Liow MH, Goh GS, Tay DK, Chia SL, Lo NN, Yeo SJ. Obesity and the absence of trochlear dysplasia increase the risk of revision in patellofemoral arthroplasty. Knee 2016;23(02):331-337 